\title{
FORMAÇÃO DOCENTE EM INÍCIO DE CARREIRA: NARRATIVAS DE PROFISSIONAIS DA REDE PÚBLICA DE JARAGUÁ-GO
}

\author{
TEACHER EDUCATION EARLY CAREER: NARRATIVES OF PROFESSIONALS FROM \\ THE PUBLIC NETWORK OF JARAGUÁ-GO
}

\author{
FORMACIÓN DOCENTE EN INICIO DE CARRERA: NARRATIVAS DE \\ PROFESIONALES DE LA RED PÚBLICA DE JARAGUÁ-GO
}

\author{
Hortência Matias de Castro \\ Universidade Estadual de Goiás - Brasil \\ José Carlos Moreira de Souza \\ Instituto Federal Goiano - Brasil
}

\begin{abstract}
Resumo: O período inicial da carreira docente é dotado de desafios, visto que o professor está aprendendo o ofício. No entanto, estudos da área têm apontado que grande parte da responsabilidade pelas dificuldades que os docentes iniciantes enfrentam é da formação inicial inadequada e descontextualizada diante da realidade, o que traz desafios à efetivação de uma prática docente eficaz. Diante disto, a presente pesquisa objetivou compreender a efetividade dos cursos de formação inicial frente aos obstáculos enfrentados pelos docentes iniciantes. Para tanto, utilizou-se de um estudo de caso com 16 professores em seus primeiros cinco anos de carreira. A partir da coleta de dados e da análise da percepção dos participantes, foi possível inferir que as contribuições da formação inicial de professores são mínimas e que, em alguns casos, são desconsideradas pelos profissionais. Ademais, foram desnudadas questões inéditas, como os desafios impostos ao professor iniciante no trabalho com alunos da Educação Especial, entre outras, que podem ser discutidas em pesquisas futuras.
\end{abstract}

Palavras chave: Professor iniciante; Dificuldades; Desenvolvimento Profissional.

\begin{abstract}
The initial period of the teaching career is endowed with challenges, since the teacher is learning the trade. However, it has been pointed out by studies in the area that a large part of the responsibility for the difficulties that beginning teachers face is due to inadequate initial training and out of context with reality, bringing adversities to the effectiveness of teaching practice. In view of this, the present research aimed to understand the effectiveness of initial training courses in the face of the challenges faced by beginning teachers, using for this purpose a case study with teachers in their first five years of career. From the data collection and based on the analysis of participants' perception, it was possible to infer that the contributions of the initial teacher training are minimal and that, in some cases, they are disregarded by the professionals. In addition, unprecedented issues were revealed that can be discussed in future research.
\end{abstract}

Keywords: Beginning teacher; Difficulties; Professional Development. 
Resumen: El período inicial de la carrera docente está dotado de desafíos, ya que el docente está aprendiendo el oficio. Sin embargo, estudios en el área han señalado que gran parte de la responsabilidad por las dificultades que enfrentan los docentes principiantes se debe a una formación inicial inadecuada y fuera de contexto con la realidad, trayendo adversidades a la efectividad de la práctica docente. Ante esto, la presente investigación tuvo como objetivo comprender la efectividad de los cursos de formación inicial ante los desafíos que enfrentan los docentes principiantes, utilizando para ello un estudio de caso con docentes en sus primeros 5 años de carrera. Con base en la recolección de los datos y en el analisis de la percepción de los participantes, se pudo inferir que los aportes de la formación inicial docente son mínimos y que, en algunos casos, son desatendidos por los profesionales. Además, se revelaron temas sin precedentes que se pueden discutir en investigaciones futuras.

Palabras clave: Maestro principiante; Desafíos; Desarrollo Profesional.

\section{Introdução}

O início da carreira docente é concebido, por vezes, como um período excepcional. No entanto, se esse momento pode ser permeado por questões motivadoras e satisfatórias, por outro lado, pode constituir-se de casos que destoam dessa realidade, porquanto os educadores não conseguem se sobressair no exercício do trabalho para o qual foram designados. Assim, vale destacar que, nessas circunstâncias, é possível encontrar relações satisfatórias ou insatisfatórias, motivadoras ou desmotivadoras, especialmente no que toca à prática pedagógica do professor recém-formado.

Diante desse cenário, com o presente estudo, pretendeu-se investigar a prática de docentes que enfrentam dificuldades em início de carreira, de forma a coletar dados para responder à problemática: Os cursos de formação têm ajudado os profissionais em início de carreira a desenvolver a prática em sala de aula? Caso sim, de que maneira?

A problemática recortada pela análise possibilitou apreender as dificuldades reveladas pelos docentes entrevistados. Além disso, permitiu avaliar os instrumentos teóricometodológicos mobilizados e/ou difundidos pelos cursos de formação de professores na expectativa de contribuir com a prática desses profissionais em sala de aula.

Como aporte teórico, esta pesquisa apresenta um referencial que considera diferentes análises interpretativas sobre os aspectos concernentes à formação docente. Nesse sentido, destacam-se aquelas contidas na concepção freiriana, apresentando direcionamentos à educação como promotora da autonomia, inclusive ao professor como intermediador deste processo. Ademais, autores como Bourdieu (1989), cuja produção teórica relaciona-se à apropriação da experiência por meio do habitus e campo, também se sobressaem na fundamentação teórica. 


\section{A formação docente e o professor em início de carreira}

A formação de professores não é uma temática de discussão ou interesse acadêmico recente, embora aparente ser, já que está em contínuo desenvolvimento e sua qualidade ainda é, por vezes, questionada, especialmente no Brasil. Historicamente, a formação docente foi alvo de debates ainda no século XVII, quando Comenius (Jan Amos Komenský, 1592-1670) preconizou sua necessidade. Quanto ao estabelecimento pioneiro para esse fim, foi criado o Seminário dos Mestres de São João Batista de La Salle, no ano de 1648, na França (SAVIANI, 2009).

Sobre o professorado no século XIX, Nóvoa (1992, p. 02) afirma que

[...] a profissão docente impregna-se de uma espécie de entredois, que tem estigmatizado a história contemporânea dos professores: não devem saber de mais, nem de menos; não se devem misturar com o povo, nem com a burguesia; não devem ser pobres, nem ricos; não são [nem] funcionários públicos, nem profissionais liberais; etc.

Notoriamente, conforme o autor destacou, esse perfil atribuído ao docente se prolongou para a história contemporânea, já que esses apontamentos são ainda hoje presentes na compreensão da formação de professores pelas políticas públicas e pelo senso comum da sociedade, o que também ajuda a contribuir para a desvalorização docente, que tem estado a crescer nos últimos anos (SANTOS, 2015).

Em continuidade, Saviani (2009) destaca que, institucionalmente, só houve uma resposta acerca da formação de professor após a Revolução Francesa, no século XIX, o que, por sua vez, passou a evidenciar a imperiosidade da instrução popular e, consequentemente, a criação de Escolas Normais para formação docente em 1795, em Paris.

É importante mencionar que as primeiras Escolas Normais possuíam nomenclaturas distintas, uma vez que as Superiores se dedicavam à formação de professores para o nível secundário, enquanto as Normais se empenhavam em formar professores para atuar no ensino primário (SAVIANI, 2009).

Tanuri (2000), na mesma linha interpretativa, aponta que, no Brasil, as Escolas Normais começaram a emergir em 1835, no Rio de Janeiro, por força da Lei n ${ }^{\circ} 10$, de 1835 . Os conteúdos curriculares dessas instituições eram restritos ao ensino primário, ou seja, a formação dos professores se articulava apenas com os conhecimentos que seriam necessários para lecionar no primário, o que restringia o acesso a outras formas de conhecimentos pelos professores.

Segundo a autora, apenas no período posterior a 1870 é que a formação de professores e as Escolas Normais começam a ganhar maior força e continuidade institucional, momento em que se "consolidam as idéias (sic) liberais de democratização e obrigatoriedade da instrução 
primária, bem como de liberdade de ensino. Antes disso, as escolas normais não foram mais que um projeto irrealizado" (TANURI, 2000, p. 64).

Ainda sobre o contexto brasileiro, Saviani (2009) resume a história da formação de professores no país em seis fases que se estendem de 1827 a 2006, relacionadas pelo autor na seguinte ordem:

1. Ensaios intermitentes de formação de professores (1827-1890). Esse período se inicia com o dispositivo da Lei das Escolas de Primeiras Letras, que obrigava os professores a se instruir no método do ensino mútuo, às próprias expensas; estende-se até 1890 , quando prevalece o modelo das Escolas Normais. 2. Estabelecimento e expansão do padrão das Escolas Normais (1890-1932), cujo marco inicial é a reforma paulista da Escola Normal tendo como anexo a escola-modelo. 3. Organização dos Institutos de Educação (1932- 1939), cujos marcos são as reformas de Anísio Teixeira no Distrito Federal, em 1932, e de Fernando de Azevedo em São Paulo, em 1933. 4. Organização e implantação dos Cursos de Pedagogia e de Licenciatura e consolidação do modelo das Escolas Normais (1939-1971). 5. Substituição da Escola Normal pela Habilitação Específica de Magistério (1971-1996). 6. Advento dos Institutos Superiores de Educação, Escolas Normais Superiores e o novo perfil do Curso de Pedagogia (1996-2006). (SAVIANI, 2009, p. 144).

Por intermédio desta contribuição do autor supracitado, compreende-se que a linha histórica da formação de professores brasileiros é demarcada por inúmeras reformas e criação de novas de instituições voltadas a essa formação. No entanto, conforme evidenciado, as Escolas Normais possuíam cunho restritivo no que diz respeito à aquisição de conhecimento pelos educadores, de modo que foram, posteriormente, substituídas pelo Magistério, momento em que o docente se formava apenas a nível médio. Este foi um período em que a formação docente se vinculou exclusivamente à formação de sujeitos para o mercado de trabalho.

Não obstante à criação dessas etapas formativas, a educação continuou a sofrer com as ameaças advindas da mercantilização das políticas educacionais e do amadorismo daqueles que estão responsáveis pelos assuntos educacionais (PARO, 2013). Confirmando tal perspectiva, Souza e Machado (2014) evidenciam que

[...] o modelo de educação que temos foi pensado e construído no momento histórico de passagem do modo de produção feudal para o capitalismo, colocando o foco na educação para o trabalho. Entretanto, não para o trabalho como princípio educativo, mas para um trabalho alienado, que forma o trabalhador para a fábrica, um operário do capital (p. 158).

Isto posto, depreende-se que a formação de professores nestes moldes é a principal responsável pelas dificuldades enfrentadas por esses profissionais nos primeiros anos de carreira, visto que a teoria, por vezes, revela um enorme distanciamento da realidade educacional brasileira. Vale ressaltar, ainda, que este quadro vem de longa data, já que, com o 
término do regime militar, inúmeras discussões em torno de uma formação de professores ampla e eficiente se destacaram. De igual modo, ressalta-se ainda que as categorias profissionais do campo educacional almejavam uma nova Lei de Diretrizes e Bases (LDB), porém foram frustradas pela de 1996, haja vista que "terceirizou" a formação de professores, conforme foi apurado por Saviani (2009), autor que afirma que,

\begin{abstract}
Introduzindo como alternativa aos cursos de pedagogia e licenciatura os institutos superiores de educação e as Escolas Normais Superiores, a LDB sinalizou para uma política educacional tendente a efetuar um nivelamento por baixo: os institutos superiores de educação emergem como instituições de nível superior de segunda categoria, provendo uma formação mais aligeirada, mais barata, por meio de cursos de curta duração (SAVIANI, 2009, p. 148).
\end{abstract}

Tais acontecimentos foram responsáveis pelas leis referentes à formação de professores que viriam no período posterior a 1996. Nesse sentido, após a LDB de 1996, surgiram outras reformas educacionais e outros dispositivos legais que passaram a orientar especificamente a formação de professores. A exemplo disso, em 2002 passaram a vigorar as Diretrizes Curriculares Nacionais para a Formação de Professores (DCN) em nível superior, as quais foram revogadas em 2015 e substituídas pelas Diretrizes Curriculares Nacionais para a formação inicial em nível superior (cursos de licenciatura, cursos de formação pedagógica para graduados e cursos de segunda licenciatura) e para a formação continuada, sendo elas também revogadas em 2019 (BRASIL, 2021).

Em 2017, emergiu a Base Nacional Comum Curricular (BNCC), almejada desde a promulgação da LDB de 1996 e que regulamentou as aprendizagens essenciais a serem trabalhadas nas escolas. Já em 2019, as novas Diretrizes Curriculares Nacionais para a Formação Inicial de Professores para a Educação Básica passaram a vigorar e a Base Nacional Comum para a Formação Inicial de Professores da Educação Básica (BNC-Formação) foi instituída.

Por fim, mais recentemente, no ano de 2020, foram instituídas as Diretrizes Curriculares Nacionais para a Formação Continuada de Professores da Educação Básica e a Base Nacional Comum para a Formação Continuada de Professores da Educação Básica (BNC-Formação Continuada) (BRASIL, 2021). Notavelmente, essas diretrizes trouxeram princípios, procedimentos e fundamentos que deveriam ser observados na organização da escola e dos currículos, bem como orientar a formação de professores para que fosse ao encontro destes pressupostos. Já a BNCC para a formação de professores é uma resolução em vigência que deve orientar a formação docente, baseando-se em três distintas dimensões: conhecimento profissional, prática profissional e engajamento profissional. 
Diante do arcabouço legal indicado, são inegáveis os esforços empregados pelo campo educacional, em conjunto com os indutores ou formuladores de políticas públicas, para que a formação de professores se desenvolva ao longo das últimas décadas. Contudo, é notório que há interesses velados, contidos nestas políticas educacionais, os quais, por vezes, apontam para a mercantilização da educação, especialmente no que concerne à formação de mão-de-obra para o chamado mercado de trabalho.

Acerca disso, Souza e Machado (2014, p. 159) enfatizam que " [...] a educação não pode estar voltada para o trabalho de forma a responder às necessidades imediatas, funcionais, de treinamento e domesticação do trabalhador”. A educação, deste modo, deve estar centrada na formação do sujeito autônomo, crítico, curioso, consciente de seu papel social, conforme afirma Freire (1996).

Para este processo de formação crítica e consciente, a mudança deve iniciar na formação de professores, esta que, por sua vez, depende de políticas públicas: a) sem interesses obscuros; b) que não engessem o trabalho pedagógico, já que ensinar é um ato puramente humano e, portanto, deve se constituir de autonomia e criticidade; c) que não estejam na contramão da formação humana não alienante.

\subsection{Caracterizando o docente em início de carreira}

O início da carreira docente é apreendido por uma parcela considerável dos profissionais, que, de algum modo, externalizam suas sensações e percepções sobre a iniciação à docência, como um período sofrível e de enfretamentos de angústias e desestímulos de toda ordem (LIMA, 2007).

Segundo Huberman (1995), os estudos sobre a carreira do professor em 1960 eram praticamente escassos e apenas se aprofundaram na década seguinte, com uma série de teóricos em todo o mundo. Apesar disso, uma questão deve ser pensada: quanto tempo um professor é considerado iniciante em sua carreira?

Huberman (1995), ao tratar do ciclo de vida do professor, esclarece que o período de entrada na carreira dura de um a três anos, porém a fase dois, da estabilização no ofício, pode acontecer entre os quatro e seis anos de trabalho, de modo que, ainda neste período, o docente enfrenta os desafios ocasionados pelo choque de realidade advindo da inserção na docência. Dessa maneira, as características de iniciação à docência estão presentes, por no mínimo, durante os cinco primeiros anos de profissão.

Ainda de acordo com Huberman (1995), o começo da carreira docente pode ser vivido de formas distintas para cada pessoa. Segundo ele, os que veem essa fase de forma positiva 
tendem a associá-la com o bom desempenho dentro de sala de aula, com o relacionamento com os alunos e com os pais, e com o apoio da instituição em que atua. $\mathrm{O}$ grupo que concebe a iniciação na docência como negativa, por outro lado, possui experiências simplesmente contrárias aos que a consideram positivas (LIMA, 2007).

A autora explicita que, entre as dificuldades iniciais do ofício, “[...] a 'campeã' parece mesmo ser a relativa à aprendizagem dos alunos. Essa está presente, de uma maneira ou de outra, com mais ou com menos intensidade, em todas as pesquisas aqui referidas" (LIMA, 2007, p. 147, grifos da autora).

Neste encadeamento teórico, a supracitada autora afirma que, além das características já mencionadas, o professor iniciante tem grande necessidade de controle da situação, de modo a possuir inseguranças e preocupações relativas à aprendizagem e aos conteúdos que, por vezes, não acontecem da forma almejada. Geralmente, estes profissionais também se submetem à opinião dos pares com mais experiência, assim como são dotados de certo conformismo em relação às regras da instituição e crenças da maioria, uma vez que desejam sempre agradar os demais.

Por estarem em fase não só de construção de sua identidade profissional, mas também pessoal, os estreantes na carreira são acometidos por influências das experiências vivenciadas enquanto alunos. Ademais, enfrentam problemas relativos à disciplina, já que ainda não possuem a percepção de sua autoridade, bem como priorizam os problemas didáticos em relação aos pessoais (LIMA, 2007).

Essa eleição das principais dificuldades da docência em início de carreira, realizada por Lima (2007), evidencia que os desafios iniciais deste ofício não são poucos e que exercem efetivamente influência sobre a prática e permanência destes professores na carreira.

Da mesma maneira, pensar o modo como o indivíduo passa a ser professor, como o exaluno se transporta para o local outrora ocupado por seu mestre, como ocorre o processo de construção da identidade profissional, momento em que se torna professor, seja aos seus olhos ou aos olhos dos outros (FONTANA, 2000), bem como os desafios que implicam o ato de ensinar que, por sua vez, também implicam o aprender a ensinar, são questões e reflexões importantes para se pensar também a formação dos docentes.

Hirst (2001) compreende o ensinar como uma atividade que pode tomar várias formas, sendo, portanto, polimorfa. $\mathrm{O}$ autor disserta que o referido termo também pode ser compreendido pela lógica de que ensinar é a prática de ensinar algo a alguém. Em tese, a grande motivação do professor para ensinar são os alunos, os quais podem alcançar um bom 
desempenho no processo pedagógico (GARCIA, 2010), ainda que outros fatores, como os salários, reconhecimento etc., exerçam influência.

Partindo desses pressupostos e se referindo especificamente à formação inicial de professores, Freire (1996) enfatiza que formar um sujeito não é treiná-lo, como tem, por vezes, acontecido nas salas de aula e nos cursos de formação. Essas práticas, segundo o autor, são inspiradas nas ideologias neoliberais que vão contra a utopia e o sonho, de modo que

[...] é preciso, sobretudo, e aí já vai um destes saberes indispensáveis, que o formando, desde o princípio mesmo de sua experiência formadora, assumindo-se como sujeito também da produção do saber, se convença definitivamente de que ensinar não é transferir conhecimento, mas criar as possibilidades para a sua produção ou a sua construção (FREIRE, 1996, p. 12).

Os apontamentos realizados por Freire instrumentalizam tanto o professor iniciante quanto os profissionais de mais experiência para a construção de uma prática educativa reflexiva, dialógica e principalmente solidária, o que, por sua vez, será um imensurável auxiliar no desenvolvimento de sua identidade docente.

\subsection{A teoria de Pierre Bourdieu: como as categorias habitus e campo repercutem na carreira docente?}

No contexto educacional contemporâneo, sob esta análise, ainda faltam ao campo as bases teóricas e conceituais para o pensamento crítico e para a técnica da problematização como formas de assimilar e apropriar-se dos conhecimentos historicamente construídos. O que se nota é a assimilação de imagens, a internalização de conceitos e a indicação de soluções imediatas. O tempo histórico atual possibilitou acostumar-se à velocidade, ao acúmulo de informações não assimiladas, as quais são reproduzidas, muitas vezes, sem reflexão.

Nesta perspectiva, as concepções de habitus e campo, formuladas por Pierre Bourdieu, ajudam a compreender como a experiência é supervalorizada pelos docentes em início de carreira, conforme destaque de Tardiff e Raymond (2000).

Isto posto, o curso de formação de professores é considerado inadequado, pois não prepara o professor para a realidade prática e suas subjetividades. Assim, ao se inserir na carreira docente e, consequentemente, em uma determina instituição de ensino, o professor iniciante se vê diante da necessidade de incorporação das normas, valores e comportamentos característicos daquele ambiente, uma vez que necessita destes instrumentos para conseguir se socializar na instituição. 
Nesta perspectiva é que emergem os conceitos de habitus e campo de Pierre Bourdieu, postulados por este teórico como ferramentas capazes de favorecer a compreensão de como ocorre o processo de aquisição da experiência pelo docente iniciante. A noção de habitus é concebida a partir da ideia de que são

[...] sistemas de disposições duráveis, estruturas estruturadas predispostas a funcionar como estruturas estruturantes, isto é, como princípio gerador e estruturador das práticas e das representações que podem ser objetivamente 'reguladas' e 'regulares' sem ser o produto da obediência a regras, objetivamente adaptadas a seu fim sem supor a intenção consciente dos fins e o domínio expresso das operações necessárias para atingi-los e coletivamente orquestradas, sem ser o produto da ação organizadora de um regente. (BOURDIEU apud ORTIZ, 1994, p. 61).

Bourdieu (1989) explica que o habitus tem grande semelhança com o termo "hábito", porém ambos se distinguem. Habitus se relaciona com o que se adquiriu e se encarnou/incorporou ao corpo de uma forma sólida/durável, tomando, portanto, a forma de disposições permanentes. Hábito, no entanto, é uma maneira de se comportar que é compreendida de forma mecânica e até automática, sendo muito mais reprodutora do que produtiva. Por exemplo, os iniciantes na profissão docente, conforme Lima (2007), têm o hábito de reproduzir práticas vivenciadas enquanto alunos; possuem, também, um enorme conformismo com as regras e crenças estipuladas pela escola pelos pares mais experientes, de modo que, são muito mais reprodutores do que produtores de novas práticas e hábitos escolares.

Já o conceito de campo também pode ser compreendido na teoria de Bourdieu, pois

[...] a noção de campo é, em certo sentido, uma estenografia conceptual de um modo de construção do objeto que vai comandar - ou orientar - todas as opções práticas da pesquisa. Ela funciona como um sinal que lembra o que há que fazer, a saber, verificar que o objeto em questão não está isolado de um conjunto de relações de que retira o essencial das suas propriedades. Por meio dela, torna-se presente o primeiro preceito do método, que impõe que se lute por todos os meios contra a inclinação primária para pensar o mundo social de maneira realista [...]: é preciso pensar relacionalmente. (BOURDIEU, 1989, p. 27).

Nessa perspectiva, o campo pode ser compreendido como um campo social diverso (campo religioso, campo educacional etc.). Nele, há determinadas condutas que estruturam as práticas de seus atores, essas que são incorporadas e repassadas aos indivíduos que se inserirem neste campo, o que pode ser compreendido como o habitus.

Em se tratando do habitus no campo educacional, pode-se afirmar que ele é o agente da prática docente, de modo que 
[...] a articulação entre as experiências de vida, a trajetória escolar, a formação acadêmica e o exercício da profissão são elementos constitutivos do habitus professoral, portanto, significativos para se pensar e reconhecer a prática pedagógica do professor/da professora. (BALDINO; DONENCIO, 2014, p. 269).

Nessa vertente, Silva (2005) esclarece que, durante a formação, é produzido e aperfeiçoado o habitus estudantil, visto que os cursos formadores de professores não ensinam o indivíduo a ser docente, mas sim a ser aluno, motivo pelo qual autores como Tardiff e Raymond (2000) apontam em suas pesquisas que o docente em início de carreira compreende que o tornar-se professor acontece apenas na prática.

Quanto ao habitus professoral, Silva (2005, p. 161) enfatiza que "o objeto de estudo das investigações sobre o ensino na sala de aula" apenas emerge e se efetiva na prática, ou seja, na inserção do ex-aluno nas funções docentes. Dessa forma, a teoria é apropriada durante o curso de formação, enquanto que a prática apenas é apreendida quando se está no exercício da carreira.

Nesta dinâmica conceitual, depreende-se que o habitus e a experiência são complementares quando se fala em formação de professores. A exemplo disto, Baldino e Donencio (2014) destacam que as experiências, saberes e conhecimentos adquiridos e internalizados pelo docente ao longo de sua carreira podem ser compreendidos como um habitus, tendo em vista que é uma forma de ser, pensar e também de agir no mundo, o que, por sua vez, pode interferir e/ou acrescentar na prática docente.

\section{Professores em início de carreira - resultados e discussão}

A presente pesquisa concentrou-se em estudar a prática dos docentes posicionados no início de carreira da cidade de Jaraguá, localizada no estado de Goiás. Neste contexto, a partir da revisão de literatura e dos apontamentos de Huberman (1995), foram selecionados 50 (cinquenta) participantes estreantes na carreira docente, ou seja, aqueles que se encontravam posicionados em seus primeiros cinco anos de carreira.

Em virtude da pandemia mundial ocasionada pelo novo Coronavírus, que causa a SARS-CoV-2 (Covid-19¹), durante o ano de 2020, que, entre outras restrições, exigiu o

1 Segundo a OMS - Organização Mundial de Saúde, a COVID-19 é uma doença causada pelo Coronavirus, denominado SARS-CoV-2, que apresenta um espectro clínico variando de infecções assintomáticas a quadros graves. c.f. ORGANIZAÇÃO PAN-AMERICANA DA SAÚDE (OPA). Coronavirus. Disponível em: https://www.paho.org/pt/topicos/coronavirus. Acesso em: 21 dez. 2020. 
distanciamento social e por essa razão a presente pesquisa se utilizou unicamente de dados coletados em um formulário eletrônico elaborado pela pesquisadora no Google Forms ${ }^{2}$.

O questionário constituiu-se de 16 (dezesseis) questões abertas e fechadas, de modo que, a partir dos dados coletados, fosse factível a compreensão da linha interpretativa do participante no tocante ao assunto tratado, possibilitando as reflexões apropriadas. Considerando tais aspectos, a análise dos dados seguiu os apontamentos de Gil (2002), de modo que, após a coleta, por meio dos questionários, foi realizada a redução dos dados, a categorização e finalmente a interpretação e a redação do texto.

É importante mencionar que a presente pesquisa delimitou o universo de participantes a 50 (cinquenta) professores, incluindo os da rede estadual e municipal da cidade de Jaraguá (GO). Para o processo de levantamento de dados, realizado entre os meses de novembro e dezembro de 2020, a presente pesquisa contou com a aprovação do Comitê de Ética em Pesquisa do IF Goiano. Do total de 50 docentes, apenas 16 profissionais demonstraram interesse em participar.

Os demais 34 contatados, não demonstraram interesse em participar de pesquisas acadêmicas em período de pandemia, alegando que já estavam sobrecarregados com as aulas ofertadas remotamente (on-line), com as cobranças da escola e com atividades e avaliações a serem corrigidas em tempo hábil, para, enfim, descansarem no recesso escolar de dezembro. Entretanto, é possível inferir que a participação nessa pesquisa, por tocar em temas que, por vezes, incomodam os profissionais, também estava condicionada à aceitação e superação de traumas e angústias já vivenciados por eles anteriormente, podendo ser essa, também, uma das razões da recusa em participar.

Nesta perspectiva, a primeira questão do formulário de coleta dos dados solicitava que os participantes descrevessem seu perfil pessoal e também profissional. Os entrevistados apresentam trajetórias singulares, ricas de narrativas pertinentes à reflexão do professor iniciante. Dentre as respostas, destacam-se aquelas emitidas pelos participantes 04 e 15 :

\footnotetext{
"Mulher, parda, classe média baixa, formada em Pedagogia, concursada e assustada diante de toda a realidade que envolve a docência e a educação" (P4).

"Sou efetiva. Penso que nosso trabalho é de grande relevância, mais do que isso, devíamos ser mais valorizados, uma vez que sempre desempenho meu trabalho de forma satisfatória" (P15).
}

2 O Google Forms "[...] é um serviço gratuito para criar formulários online. Nele, o usuário pode produzir pesquisas de múltipla escolha, fazer questões discursivas, solicitar avaliações em escala numérica, entre outras opções. " (TECHTUDO, 2018). c.f. TECHTUDO. Google Forms: o que é e como usar o app de formulários online (2018). Disponível em: https://www.techtudo.com.br/dicas-e-tutoriais/2018/07/google-forms-o-que-e-e-comousar-o-app-de-formularios-online.ghtml. Acesso em: 17 set. 2020. 
A narrativa da participante 4 apresenta uma questão interessante, uma vez que esse sentimento de "susto" que ela apontou sentir diante da realidade escolar complementa fundamentalmente as menções de Huberman (1995) sobre o "choque do real" em início de carreira, permitindo, assim, reflexões sobre o distanciamento entre a formação e a realidade.

Posteriormente, a segunda questão indagou os participantes acerca de sua formação e atuação, de modo que se destacam as narrativas dos professores 1 e 2, os quais, ao apresentarem seu perfil no questionamento anterior, mencionaram ser do sexo masculino:

\section{"Licenciatura Plena em Matemática” (P1).}

"Licenciado em História - 3 anos" (P5).

Analisando as respostas, verifica-se que, dos 16 participantes, apenas 2 eram homens (conforme destaque acima) e ambos em áreas especificas (História e Matemática), o que sugere concordância com Castro e Santos (2016) que argumentam a escolha da Pedagogia pelas mulheres em função dos aspectos culturais relacionados ao maternalismo natural.

Essa compreensão também se relaciona com a concepção de habitus descrita por Bourdieu (1989), uma vez que a sociedade, as instituições, bem como a categoria/grupo de professores, já reproduzem mecanicamente a crença de uma relação maternalmente natural entre a mulher e a profissão docente.

A partir das narrativas também é possível compreender que todos os participantes da pesquisa estão posicionados dentro da triangulação de tempo relativo ao período de iniciação e estabilização na carreira, cinco anos de carreira, conforme Huberman (1995).

Em seguida, buscou-se capturar dados sobre o vínculo empregatício destes profissionais, tendo em vista que a educação brasileira atualmente convive com diferentes relações trabalhistas, com destaque para os professores temporários, sem estabilidade, e os professores efetivos na carreira docente, que são estáveis para o exercício de suas funções:

Gráfico 1- Vínculo empregatício dos participantes

Qual vínculo empregaticio mantém com a instituição educacional em que trabalha? 16 respostas
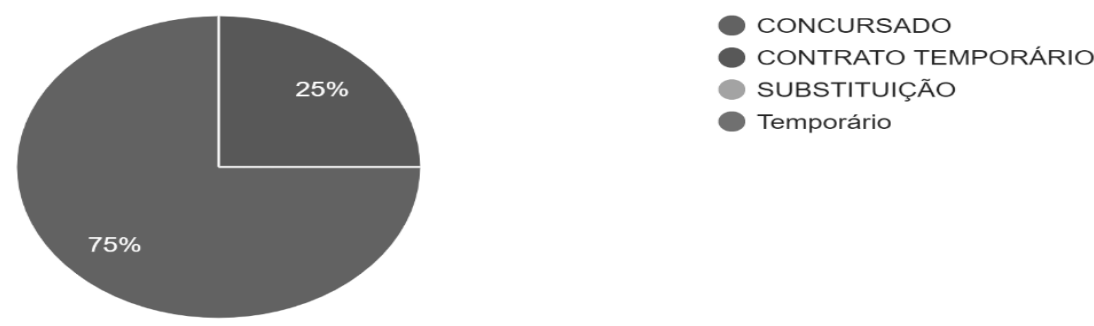

Fonte: Elaboração da autora a partir dos dados da pesquisa, novembro de 2020. 
O vínculo de trabalho dos entrevistados revela que $75 \%$ são profissionais efetivos e, portanto, com plano de carreira e estabilidade profissional garantida. Já os outros $25 \%$, equivalente a quatro profissionais, estão em contrato temporário com a Secretaria Estadual de Educação de Goiás.

Acerca dos contratos temporários de trabalho docente, Bosi (2007) compreende que os mesmos tendem a contribuir com a precarização do trabalho docente, visto que esta modalidade contratual não oferta direitos trabalhistas e tampouco a estabilidade necessária para um trabalho docente crítico e sem retaliações.

A estabilidade, embora esteja sendo, dia após dia, ameaçada de extinção pelas reformas políticas, é uma das ferramentas mais democráticas no exercício da prática docente, uma vez que, por meio dela, o professor/trabalhador possui a garantia que a exposição de suas ideologias e/ou a revelação da compreensão de mundo não serão acarretadoras da perda de seu sustento/trabalho. Assim, de forma geral, a estabilidade é um "grito de liberdade" dentro de um sistema político em que o professor é, por vezes, considerado um "vilão".

Quanto ao preparo para o ingresso na carreira, $81,25 \%$ dos sujeitos entrevistados afirmaram que se sentiam despreparados para o ingresso na carreira, enquanto que $18,75 \%$ disseram estar preparados. Ressalta-se, porém, que, em outras questões, os entrevistados afirmam que enfrentaram dificuldades diversificadas. É possível deduzir que tais afirmações revelam uma contradição ao mencionarem que os desafios enfrentados se justificam por conta de a noção de sala de aula antes do ingresso no ofício ser muito abstrata em relação à realidade, conforme Tardiff e Raymond (2000).

Quanto à efetividade dos cursos de formação inicial em relação à capacitação/qualificação do docente iniciante, apenas $25 \%$ dos sujeitos entrevistados a avaliam positivamente no tocante a tais práticas. Destaca-se a narrativa do participante 5 , o qual relata que:

"Não - faltou prática em sala de aula, algo que é pouco explorado no estágio. O estágio é muito fraco e falho" (P5).

Este foi um dos sujeitos que afirmou anteriormente estar preparado para a realidade de sala de aula, mas que, neste questionamento, aponta para afirmativas contrárias, de maneira, inclusive, a tecer críticas ao estágio supervisionado. Diante disto, Fontana (2000) reflete que

[...] enquanto no aprendizado artesanal o mestre de ofício capacitava-se pelo trabalho e ensinava seus aprendizes no trabalho, olhando primeiro e produzindo em seguida, aprendendo a um só tempo os segredos de seu fazer e os comportamentos necessários a seu trabalho, na nossa escola busca-se disciplinar, conformar os impulsos, os desejos, as vontades do corpo, tendo 
em vista determinados modos de operar genéricos - atenção, prontidão, rapidez (FONTANA, 2000, p. 109).

Considerando a reflexão desta autora e a cítrica elaborada pelo entrevistado P5, compreende-se que talvez esta seja uma das grandes justificativas para a profissão docente ser uma das carreiras mais solitárias que se conhece. O professor aprende na solidão de suas dificuldades, por meio dos erros e dos acertos, do tentar e do desistir.

Por outro lado, o participante 11 afirma que a falha em sua formação também pode ser justificada pela falta de capacitação dos professores da graduação. Sobre isto, Bosi (2007) enfatiza que, com a flexibilização das leis trabalhistas, o número de docentes tem aumentado ao longo dos anos, porém este índice nem sempre é acompanhado de qualidade e de capacitação. Compreende-se que tais percepções merecem reflexões em pesquisas futuras.

Neste seguimento, o próximo questionamento solicitava que o participante indicasse se enfrentou dificuldades em seu início de carreira docente, conforme demonstrado no gráfico:

Gráfico 2- Você enfrentou dificuldades no início de carreira?

Inicio docente será aqui determinado como os 5 primeiros anos de docência, responda: você enfrentou/enfrenta dificuldades no início da sua carreira docente? 16 respostas
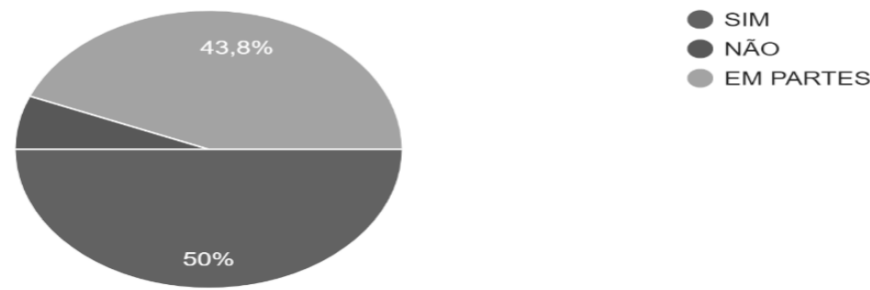

Fonte: Elaboração da autora a partir dos dados da pesquisa, novembro de 2020.

Do total de participantes, apenas um participante afirmou não ter enfrentado dificuldades em início de carreira, ao passo que a expressiva maioria $(93,8 \%)$ revelou ter enfrentado dificuldades, mesmo que parcialmente. Essas afirmativas são semelhantes às apresentadas por outros autores da área, como Lima (2007), Colombo Júnior (2009), Huberman (1995), dentre outros.

Por conseguinte, quanto ao relato das principais dificuldades enfrentadas, $93,75 \%$ dos entrevistados indicaram ter encontrado algum tipo de adversidade neste período. Nesse sentido, destaca-se a fala do participante 1:

"O que me preocupava, e às vezes eu até perdia o sono, quando percebia que os alunos não tinham entendido o conteúdo. Então aquilo ficava martelando na minha cabeça, e eu ficava pensando de que maneira poderia mediar aquele conhecimento" $(P 1)$. 
Isto se dá pelo fato de que os desafios e dificuldades vivenciados no início da carreira afetam, inclusive, a vida pessoal e até mesmo o estado fisiológico do docente, neste caso o sono. Sobre isto, cita-se novamente Lima (2007) em sua afirmação de que, em início de carreira, os docentes tendem a priorizar os problemas didáticos em detrimento dos problemas pessoais. Em consonância a isso, apenas $6,25 \%$ dos entrevistados mencionaram ter sido tranquilo a iniciação.

Tal afirmativa demonstra que, embora seja comum encontrar dificuldades no início da carreira profissional, isto de forma alguma pode ser generalizado, visto que, conforme Garcia (1999), o docente pode enfrentar desafios em momentos distintos da carreira, como na mudança de níveis de ensino, a título de exemplo. Assim, é importante ainda destacar que, esses desafios, muitas vezes, implicam em aprendizagem e desenvolvimento.

Quanto às principais dificuldades evidenciadas pelas narrativas dos professores, percebe-se que todas vão ao encontro do levantamento feito por Fontana (2000) e Lima (2007), especialmente aquelas que se referem $\mathrm{a}(\mathrm{o})$ : a) dificuldade de manter a disciplina; b) preocupação com a aprendizagem do aluno; c) distanciamento entre teoria e prática; d) a falta de experiência; e) insegurança dos professores diante da realidade; f) ausência de apoio da família e da equipe pedagógica; g) desvalorização do professor, entre outros.

Diante de todas essas dificuldades, é essencial que o iniciante tenha o apoio da instituição. Para Lima (2007), esse apoio é fundamental para a permanência ou não na docência, visto que, por meio dele, o docente se sentirá acolhido entre seus pares, de modo a adquirir maior segurança no desenvolvimento de seu trabalho.

Por outro lado, conforme demarca Fontana (2000), a relação do professor estreante com a equipe gestora, por vezes, tende a ser conflituosa, uma vez que o iniciante não possui as expertises que muitas vezes são almejadas pelo chefe imediato. Em outras palavras, a equipe escolar, muitas vezes, tem a expectativa e o desejo de que o iniciante já comece sua carreira com o habitus estruturado, podendo ser essa a razão de grande parte dos conflitos entre os atores

Em continuidade, foi indagado quais são as motivações para permanência na carreira:

Gráfico 3- As motivações para permanência na carreira.

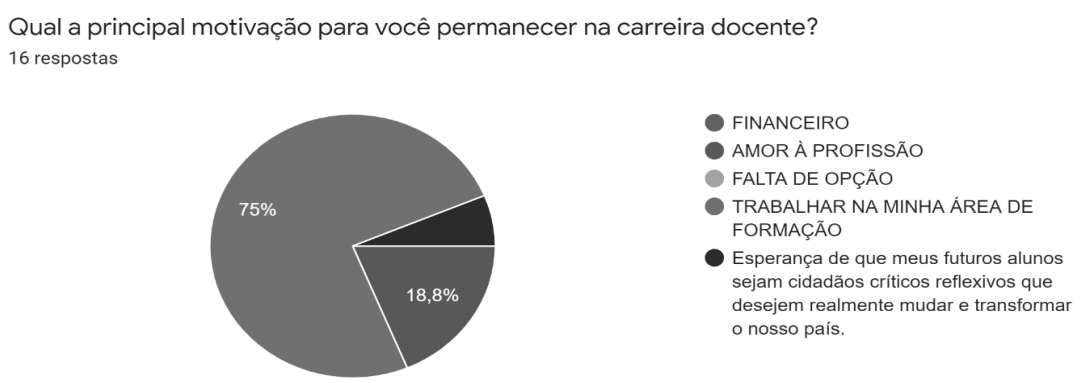

Fonte: Elaboração da autora a partir dos dados da pesquisa, novembro de 2020. 
A análise do gráfico indica que 12 dos 16 participantes enfatizam que a principal justificativa para permanência na carreira, mesmo com todos os desafios e dificuldades, é a possibilidade de se trabalhar na área de formação, o que geralmente é valorizado para profissionais iniciantes. Lima (2007) concebe que isto acontece devido ao sentimento de descoberta que toma conta do professor. Em concordância, Huberman (1995) afirma que o período da descoberta permite que o docente suporte o período da sobrevivência.

$\mathrm{Na}$ sequência, buscou-se compreender a percepção dos participantes acerca da superação dos desafios iniciais do ofício:

Gráfico 4- A superação das dificuldades da profissão

Você acredita que as dificuldades iniciais da profissão docente serão superadas? 16 respostas

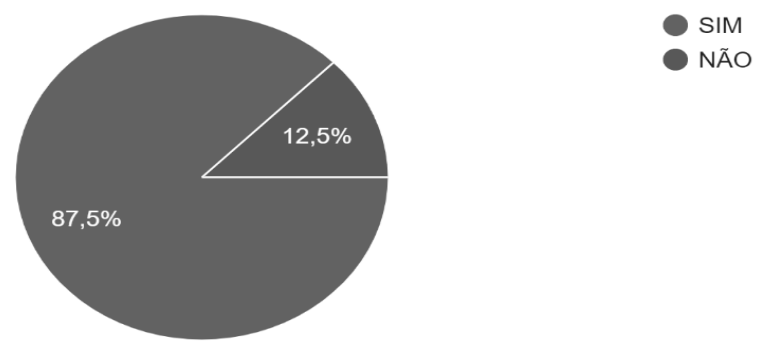

Fonte: Elaboração da autora a partir dos dados da pesquisa, novembro de 2020.

Com o auxílio do gráfico 4 , infere-se que, para a maioria dos participantes $(87,5 \%)$, os desafios iniciais da carreira docente podem ser superados. Apenas 12,5\% afirmam que os desafios não são superados, demonstrando a compreensão de que a complexidade dos desafios docentes é recorrente em qualquer fase da carreira.

Para Fontana (2000, p. 109), “a professora não está pronta em nós, quando começamos a trabalhar. Pensando bem, não está pronta nunca, por mais estáveis, duráveis e semelhantes que pareçam ser nossas características como profissionais." Do mesmo modo, cita-se, novamente, Garcia (1999) que enfatiza que os desafios da carreira docente podem se manifestar a qualquer tempo ao longo do exercício do profissional, tendo em vista que as configurações da carreira são constantes.

Seguidamente, os participantes foram questionados sobre a sintonia entre a fundamentação teórica dos cursos de formação e a realidade escolar, já que os cursos de formação docente, conforme os apontamentos anteriores da literatura da área, possuem momentos escassos de interação entre teoria e prática. O gráfico que segue ilustra a percepção dos entrevistados: 
Gráfico 5- Sintonia dos cursos de formação de professores com a realidade da sala de aula.

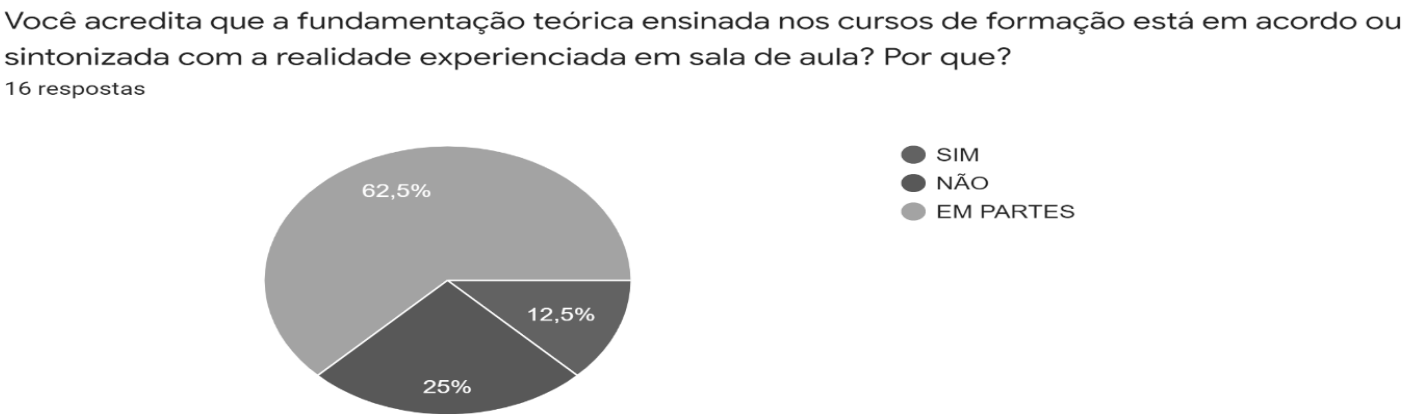

Fonte: Elaboração da autora a partir dos dados da pesquisa, novembro de 2020.

Os resultados encontrados na presente pesquisa estão em acordo com os achados de Tardiff e Raymond (2000), estudo no qual os docentes iniciantes possuem a concepção de que os cursos de formação inicial são descontextualizados da realidade escolar, uma vez que a teoria não se mostra em articulação com a prática.

Além disto, os autores destacam que muitos destes profissionais, frente às dificuldades, chegam a criticar e, por vezes, desconsiderar a efetividade da formação inicial, compreendendo a experiência como fator de maior relevância em início de carreira e a formação a nível superior como um apêndice. Refletindo sobre isto, é possível compreender que os profissionais têm essa concepção justamente porque a experiência não foi construída, no âmbito da formação inicial, mediante a articulação entre teoria e prática, que permite tanto a mobilização quanto o desenvolvimento de competências base para a identidade profissional docente.

Isto posto, o questionamento seguinte buscou compreender quais ações/atitudes/ferramentas, na concepção dos participantes, são (ou foram) fundamentais para que os mesmos passassem pelo período inicial e fosse possível a superação das dificuldades advindas:

Gráfico 6- Contribuições para a superação das dificuldades iniciais da carreira.

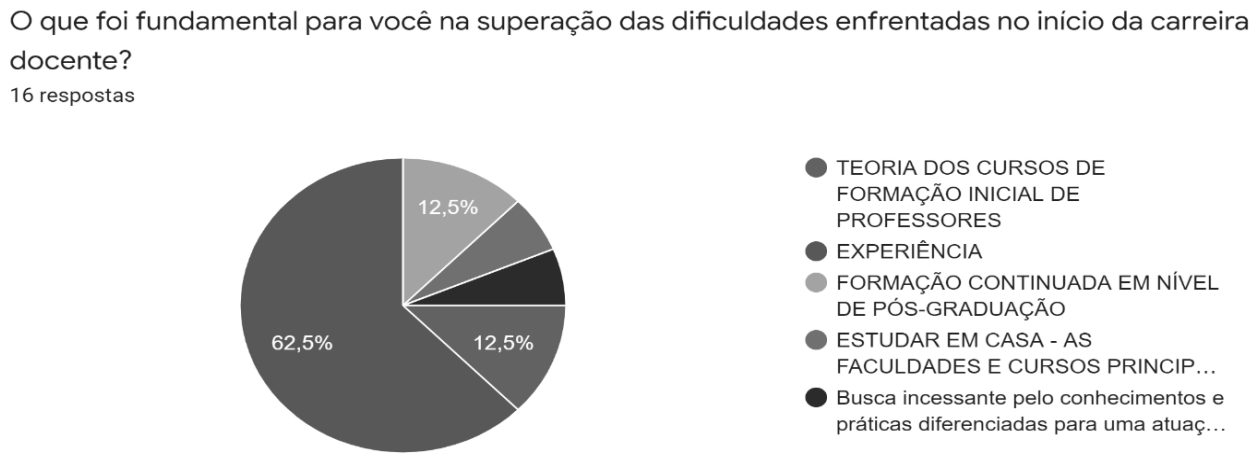

Fonte: Elaboração da autora a partir dos dados da pesquisa, novembro de 2020. 
A partir do gráfico, depreende-se que, novamente, os resultados da presente pesquisa se relacionam com a pesquisa de Tardiff e Raymond (2000), uma vez que, assim como no estudo dos autores, constatou-se que os profissionais têm a percepção de que a experiência é o fator primordial para a superação das dificuldades advindas da inserção na carreira docente. Nesse sentido, os autores declaram que "para os professores de profissão, a experiência de trabalho parece ser a fonte privilegiada de seu saber-ensinar" (TARDIFF; RAYMOND, 2000, p. 213).

Além disso, neste questionamento, um dos participantes destacou que a principal fonte de superação das dificuldades da inserção na carreira foi:

"Estudar em casa - as faculdades e cursos principalmente na área de história se tornaram militância pró ideológica” (P5).

Em vista disto, esse destaque direcionado aos cursos de formação inicial merece ser discutido em pesquisas futuras, uma vez que apresenta potencial investigativo para a compreensão dos caminhos que os cursos de formação estão trilhando.

Posteriormente, os participantes foram questionados acerca da formação continuada. Todos os participantes manifestaram que estão inseridos nestes cursos:

Gráfico 7- Participantes inseridos na formação continuada.

Você cursou, está cursando ou pretende cursar um curso de formação continuada? 16 respostas

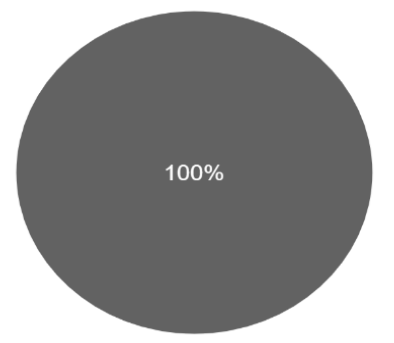

Fonte: Elaboração da autora a partir dos dados da pesquisa, novembro de 2020.

Diante deste cenário, compreende-se que a tese de Gatti (2008) deve ser considerada, uma vez, para a autora, a procura pela formação continuada é, por vezes, concebida como uma forma de compensação da formação inicial falha. Nestes moldes, a formação continuada tem figurado como um remédio para a formação inicial inadequada, especialmente frente aos desafios cotidianos da escola.

De igual modo, os participantes também responderam sobre a aplicabilidade da teoria do curso de formação de professores em suas práticas pedagógicas, conforme expressa o gráfico $8:$ 
Gráfico 8- Aplicabilidade teórica do curso de formação na prática docente.

Em uma escala de o a 10, responda: Qual a aplicabilidade da teoria do curso de formação de professores em sua prática pedagógica diária?

16 respostas

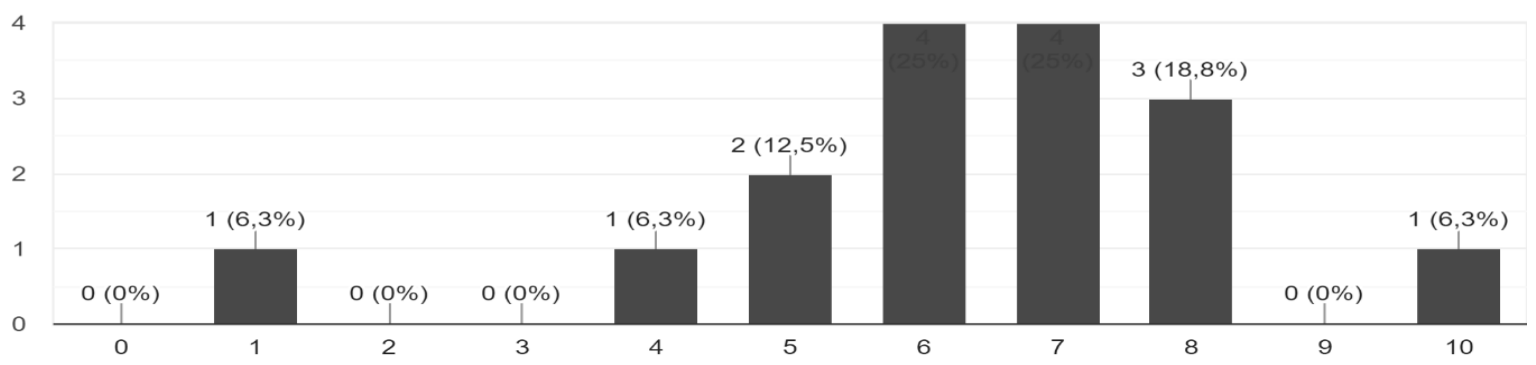

Fonte: Elaboração da autora a partir dos dados da pesquisa, novembro de 2020.

O gráfico 8 demonstra que os participantes reconhecem a aplicabilidade da teoria propiciada pelos cursos de formação inicial de professores em sua respectiva prática pedagógica, porém apenas um participante revelou que compreende a teoria aplicável na íntegra ao seu fazer docente. Embora os índices apresentem uma média, é relevante mencionar que essa aplicabilidade ainda está abaixo do almejado.

Sequencialmente, objetivou-se descobrir a percepção dos participantes sobre a relação dos conceitos teóricos aprendidos no curso de formação inicial com a prática diária:

Gráfico 9- Percepção sobre a relação dos conceitos teóricos da formação com a prática diária.
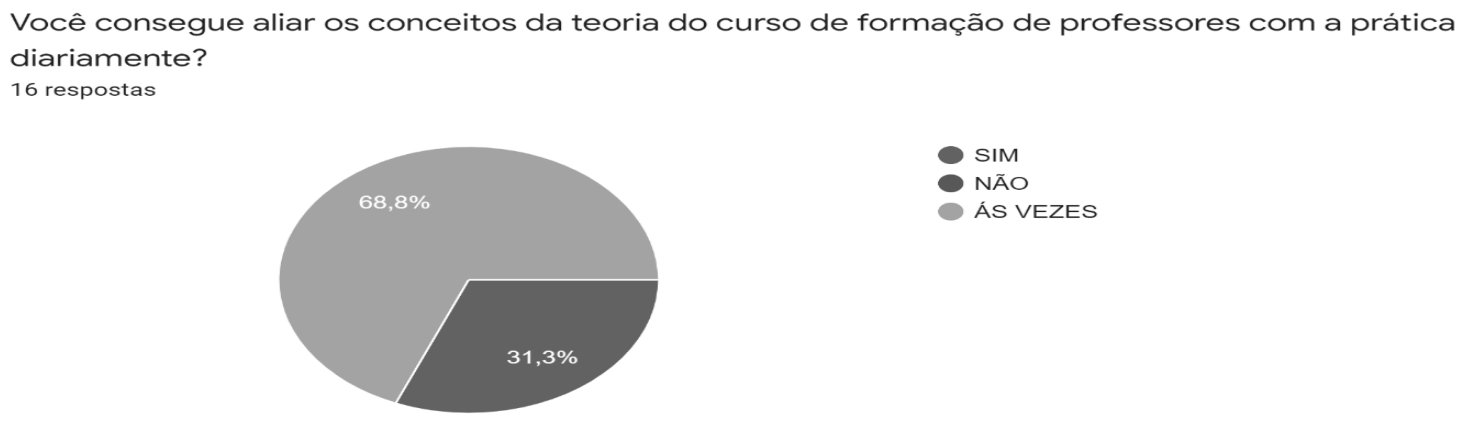

Fonte: Elaboração da autora a partir dos dados da pesquisa, novembro de 2020.

Assim como revelado no questionamento anterior, esta indagação da percepção do entrevistado em relação aos conceitos teóricos e à prática apresenta resultados medianos, que não são negativos, porém que também não são positivos, visto que, na formação inicial, o futuro professor tem contato com uma formação teórica composta por inúmeros conceitos, mas que, na compreensão dos entrevistados, não são totalmente úteis na prática docente cotidiana.

Ainda se tratando dos questionamentos, foi solicitado que os participantes respondessem acerca do auxílio dispensado pelos cursos de formação inicial ao professor estreante: 
Gráfico 10- Auxílio dispensado pelos cursos de formação inicial ao professor estreante.

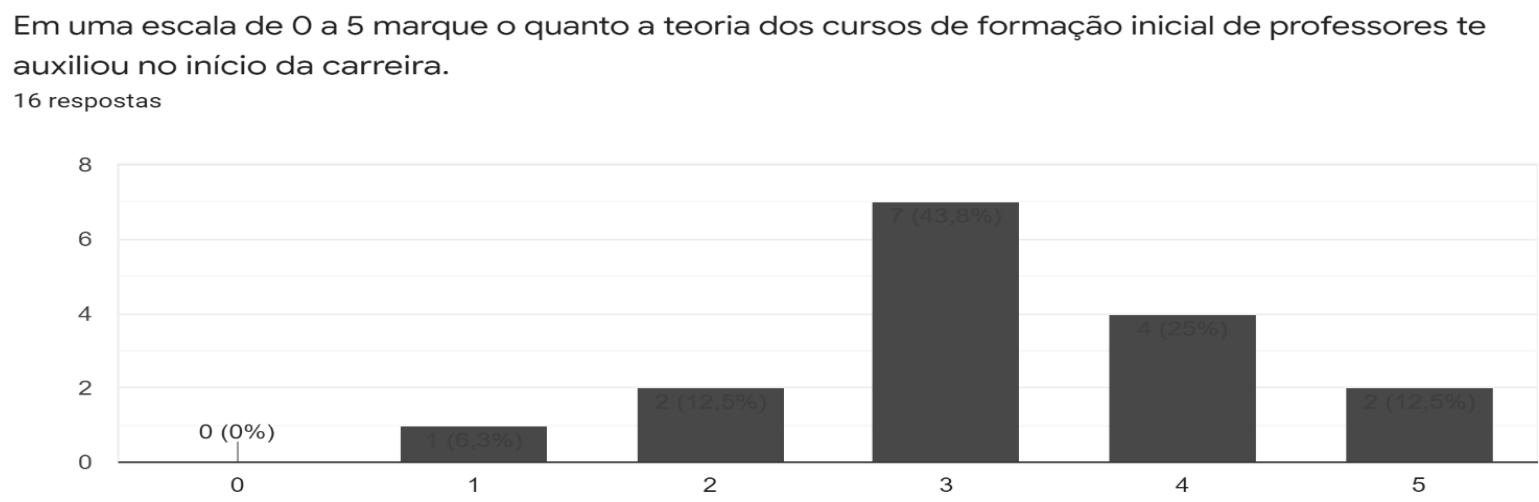

Fonte: Elaboração da autora a partir dos dados da pesquisa, novembro de 2020.

Com estes dados, reitera-se a percepção de que o início da carreira é um período que pode ser considerado solitário, já que o docente iniciante chega à escola com um vazio prático e, por vezes, também teórico, afinal a teoria que não consegue se correlacionar com a prática se mostra ineficiente e pouco aplicável.

No questionamento seguinte, os participantes foram convidados a descrever suas principais desmotivações no que concerne à carreira docente. As respostas mais recorrentes foram as seguintes:

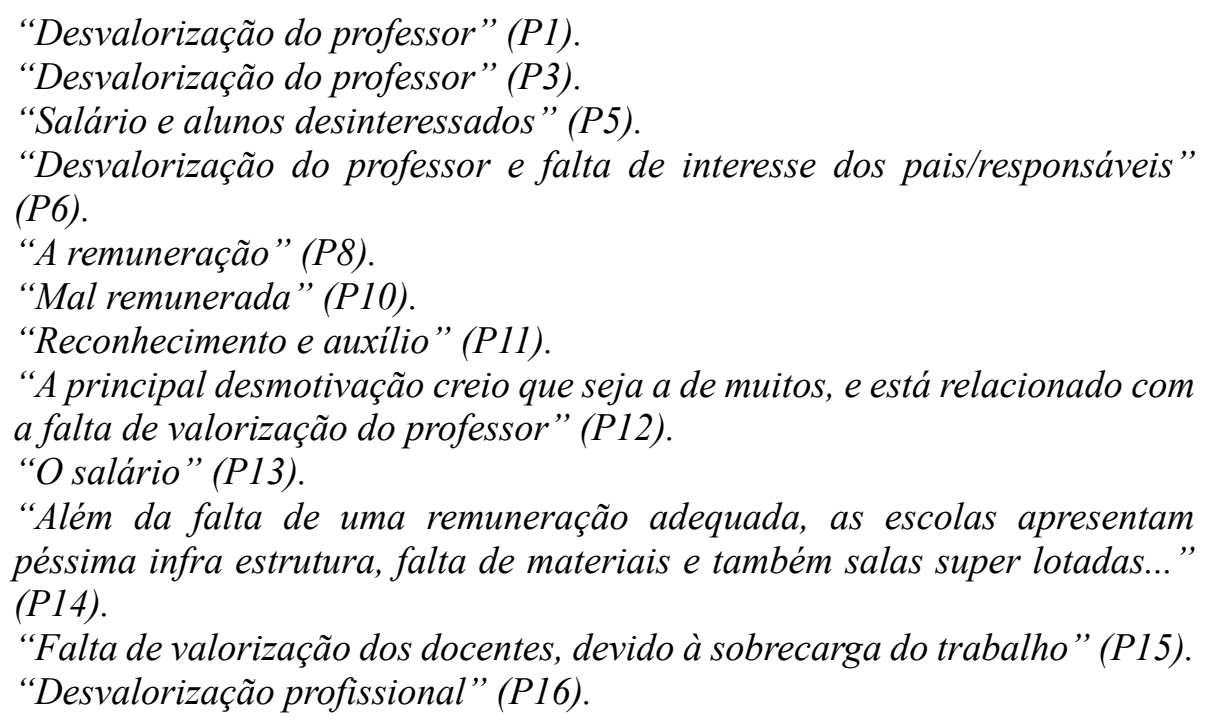

É perceptível nas narrativas dos profissionais que a principal desmotivação em relação à carreira docente remonta a desvalorização do professor na sociedade contemporânea. $\mathrm{O}$ destaque das respostas emitidas pelos entrevistados está no tocante à remuneração, que é baixa no Brasil. Atualmente, o piso salarial para professores iniciantes é de $\mathrm{R} \$ 2.886,24$ (dois mil e oitocentos e oitenta e seis reais e vinte e quatro centavos) para 2020, segundo o MEC Ministério da Educação. 
Entretanto, a desvalorização docente não se restringe à remuneração, porquanto alcança outras esferas. Na perspectiva formulada por Santos (2015), a desvalorização docente possui cinco tipos distintos, sendo: o econômico (remuneração), social (desprestígio), psicológico (autodesvalorização), obsolência (profissão obsoleta), desqualificação (retirar o valor da profissão). Todas são citadas pelos participantes da investigação.

Por fim, os profissionais foram convidados a descrever as experiências que tiveram até o momento, havendo abertura para apresentarem narrativas sobre questões exitosas que vivenciaram, bem como narrar seus principais desafios, dificuldades e sugerir adequações aos cursos de formação, de forma que a teoria trabalhada por eles ficasse mais próxima à realidade do ofício, conforme pode ser conferido nas falas de três entrevistados, destacadas a seguir:

\begin{abstract}
"Sou novata, mas nesses quase 5 anos como professora posso garantir que até mesmo os professores mais experientes estão também desorientados porque a escola mudou, as crianças mudaram é uma nova geração que exige um novo modo de aprendizado, pais que que cobram dos docentes o progresso de ensino aprendizagem e não de seus filhos, crianças que chegam sem nenhuma autonomia na escola, totalmente dependentes dos pais, mas que ao mesmo tempo tão frágeis se tornam donas da vida dos mesmos. Infelizmente é algo mais amplo e complexo que um curso de formação, mas acredito que é preciso que se abordem nesses cursos questões como a responsabilidade familiar na escola, não romantizar o curso pois de fato pedagogia não é um curso vocacional e por fim acho que é fundamental que a classe dos professores aprenda sobre empatia porque não podemos cobrar valorização de ninguém se não há união entre nós" (P2).
\end{abstract}

"A minha experiência profissional é vivenciada dia após dia, pois estou em aprendizado constante. Os cursos de formação de professores deveriam ter laboratórios de aulas práticas onde pudessem preparar os futuros docentes adequadamente para a realidade da sala de aula. Trabalhar de forma conjunta a teoria e a prática" (P6).

"Penso que deveriam ofertar metodologias didáticas que nos ajudassem nesse sentido, a melhorar o desempenho em sala de aula, repensando a educação sob vários aspectos. Tive muitas dificuldades porque senti como se tivesse caído numa área que até então desconhecia" (P8).

O participante também 12 chamou a atenção para a realidade da sala de aula que é divergente daquela descrita nos cursos de formação. O distanciamento da realidade escolar e da formação está precisamente nessa concepção fantasiosa de sala de aula que o futuro docente conhece por meio das teorias em seu processo formativo. Essa ilusão apenas deixa de existir quando ele se depara com a realidade cotidiana, momento em que acontece o supracitado choque de realidade.

Nesta mesma linha interpretativa, o participante 6 chama atenção para a realidade vislumbrada em sala de aula, que é divergente daquela descrita nos cursos de formação, já que 
estes deveriam ser uma espécie de laboratório para a formação do futuro professor. Da mesma forma, ressalta-se a leitura do participante 2, que enfatiza: "não se deve romantizar o curso, pois de fato pedagogia não é um curso vocacional”. Nessa fala, é perceptível uma ruptura de crenças e concepções, uma vez que a divergência existente na formação, que tende a romantizar o curso por meio da realidade constituída por grandes desafios nem sempre abordados com a profundidade devida por parte dos programas de formação inicial, é constatada na narrativa do participante.

\section{Considerações finais}

Conclui-se que efetivamente os professores em início de carreira enfrentam dificuldades, uma vez que os dados coletados, bem como as referências consultadas, pontuam isso. Outrossim, grande parte dos participantes aponta para um abismo entre a formação inicial e a realidade encontrada e vivenciada em sala de aula, o que é sugerido como uma das razões das dificuldades enfrentadas.

No que concerne ao problema levantado inicialmente pela presente pesquisa, é possível inferir que a formação inicial de professores dispõe de uma base para a atuação docente, porém, no que diz respeito à prática diária da docência e aos desafios relativos à sala de aula, os entrevistados são enfáticos ao afirmar que essas contribuições são mínimas.

Os professores entrevistados também apontam para uma superioridade da experiência em detrimento da formação de professores, mas tal concepção é incoerente, visto que essa formação deve ser vista e validada como um continuum da carreira docente, ou seja, ambas se complementam, todavia uma não substitui a outra, conforme Fontana (2000).

$\mathrm{Na}$ análise das narrativas dos professores pesquisados, é perceptível que os docentes foram alvo de todas as cinco formas de desvalorização desses profissionais citadas por Santos (2015), embora a desvalorização de cunho econômico, mencionada explicitamente cinco vezes, e a social sejam as mais citadas, afinal são as mais aparentes e populares na sociedade.

De forma geral, a presente pesquisa traz contribuições importantes no tocante às percepções dos professores sobre o início de carreira e aos desafios enfrentados neste período. Além do mais, ela desnuda temas relevantes que merecem ser tratados em pesquisas futuras, como: a) os desafios do professor iniciante em lidar com alunos da Educação Especial; b) a formação inadequada de professores nos cursos de formação docente; c) as ideologias nos cursos de formação; d) as políticas educacionais contemporâneas de cunho tecnicista.

Por fim, compreende-se que o presente estudo demonstra a relevância das pesquisas sobre a formação de professores, uma vez que trouxe representatividade ao tema e às narrativas 
de professores iniciantes, narrativas estas que foram capazes de expressar ricas experiências e percepções sobre este período desafiador, principalmente no que diz respeito à formação inicial e à atuação profissional.

\section{REFERÊNCIAS}

BALDINO, J. M.; DONENCIO, M. C. B. O habitus professoral na constituição das práticas pedagógicas. Polyphonía, v. 25, n. 1, p. 263-281, jan./jun., 2014. Disponível em: $<$ https://www.revistas.ufg.br/sv/article/viewFile/38563/19509>. Acesso em: 20 dez. 2020.

BOURDIEU, P. O poder simbólico. Rio de Janeiro: Bertrand Brasil, 1989.

BOSI, A. de P. A precarização do trabalho docente nas instituições de ensino superior do Brasil nesses últimos 25 anos. Educação e Sociedade, Campinas, v. 28, n. 101, p. 1503-1523, dez. 2007. Disponível em $<\mathrm{http}$ ://www.scielo.br/scielo.php?script=sci_arttext\&pid=S0101$73302007000400012 \& \operatorname{lng}=\mathrm{en} \& \mathrm{nrm}=\mathrm{iso}>$. Acesso em: $27 \mathrm{dez} .2020$.

BRASIL. Ministério da Educação. Formação Superior para a Docência na Educação Básica. Disponível em: http://portal.mec.gov.br/pet/323-secretarias-112877938/orgaosvinculados-82187207/12861-formacao-superior-para-a-docencia-na-educacao-basica. Acesso em: 17 dez. 2020.

CASTRO, R. P. de; SANTOS, V. R. dos. Relações de gênero na Pedagogia: concepções de estudantes homens. Educação em Perspectiva, Viçosa, v. 7, n. 1, p. 53-76, 2016. DOI: 10.22294/eduper/ppge/ufv. v7i1.720. Disponível em:

https://periodicos.ufv.br/educacaoemperspectiva/article/view/6859. Acesso em: 23 dez. 2020

COLOMBO JUNIOR, P. D. Enfim Professor. E agora? Alexandria, Florianópolis, v. 2, n. 1, p. 27-44, 2009. Disponível em:

https://periodicos.ufsc.br/index.php/alexandria/article/view/37913. Acesso em: 23 dez. 2020.

FONTANA, R. C. Trabalho e subjetividade. Nos rituais da iniciação, a constituição do ser professora. Caderno CEDES, Campinas, v. 20, n. 50, p. 103- 119, 2000.Disponível em: https://www.scielo.br/scielo.php?pid=S0101-

32622000000100008\&script=sci_abstract\&tlng=pt. Acesso em: 17 ago. 2020.

FREIRE, P. Pedagogia da autonomia: saberes necessários à prática educativa. 25. ed. São Paulo: Paz e Terra, 1996.

GIL, A. C. Como elaborar Projetos de Pesquisa. 4. ed. São Paulo: Atlas, 2002.

GARCIA, C. M. Formação de professores. Para uma mudança educativa. Porto: Porto Editora, 1999.

GARCIA, C. M. "O professor iniciante, a prática pedagógica e o sentido da experiência". Revista Brasileira de Pesquisa sobre Formação Docente, Belo Horizonte, v. 2, n. 3, p. 1149, 2010. Disponível em: https://revformacaodocente.com.br/index.php/rbpfp/article/view/17. Acesso em: 17 ago. 2020.

GATTI, B. A. Análise das políticas públicas para formação continuada no Brasil, na última década". Revista Brasileira de Educação, Rio de Janeiro, v. 13, n. 37, p. 57-70, abr. 2008. 
Disponível em $<\mathrm{http}: / / \mathrm{www}$. scielo.br/scielo.php?script=sci_arttext\&pid=S1413$24782008000100006 \& \operatorname{lng}=$ pt\&nrm=iso $>$. Acesso em: 05 jan. 2021.

HIRST, P. H. O que é ensinar? In: POMBO, O. (org.). Cadernos de História e Filosofia da Educação: Educar/Ensinar. Lisboa: Ed. Departamento de Educação da Faculdade de Ciências de Lisboa, 2001. Disponível em:

http://www.educ.fc.ul.pt/docentes/opombo/hfe/cadernos/ensinar/hirst.pdf. Acesso em: 14 dez. 2020.

HUBERMAN, M. O ciclo de vida profissional dos professores. In: NÓVOA, António (org.). Vidas de professores. Porto/Portugal: Porto, 1995.

LIMA, E. F. et al. Sobrevivendo ao início da carreira docente e permanecendo nela. Como? Por quê? O que dizem alguns estudos. Educação \& Linguagem, v. 10, n. 15, p. 138$160,2007$.

NÓVOA, A. Formação de professores e profissão docente. In: NÓVOA, A. (Coord.). Os professores e sua formação. Lisboa: Dom Quixote, 1992. Disponível em: https://core.ac.uk/download/pdf/12424596.pdf. Acesso em 14 dez. 2020.

ORTIZ, R. A procura de uma sociologia da prática. In: ORTIZ, R. (org.). Pierre Bourdieu. São Paulo: Editora Ática, 1994.

PARO, V. H. O professor como trabalhador: implicações para a política educacional e para a gestão escolar. 2013. Disponível em: http://www.vitorparo.com.br/wpcontent/uploads/2019/10/capitulo-2-o-professor-como-trabalhador.pdf. Acesso em: 14 dez. 2020 .

SANTOS, W. A. Uma reflexão necessária sobre a profissão docente no Brasil, a partir dos cinco tipos de desvalorização do professor. Sapere Aude, Belo Horizonte, v. 6, n.11, p. 349$358,2^{\circ}$ sem., 2015.

SAVIANI, D. Formação de professores: aspectos históricos e teóricos do problema no contexto brasileiro. Revista Brasileira de Educação, Rio de Janeiro, v. 14, n. 40, pág. 143155, abr. 2009. Disponível em

$<$ http://www.scielo.br/scielo.php?script=sci_arttext\&pid=S1413-

$24782009000100012 \& \operatorname{lng}=\mathrm{en} \& \mathrm{nrm}=\mathrm{iso}>$. Acesso em: 15 dez. 2020.

SILVA, M. da. O habitus professoral: o objeto dos estudos sobre o ato de ensinar na sala de aula. Revista Brasileira de Educação, Rio de Janeiro, n. 29, p. 152-163, ago. 2005.

SOUZA, J. C. M. de; MACHADO, M. M. O (não) lugar da educação dos jovens trabalhadores. Revista Educativa: Revista de Educação, Goiânia, v. 17, n. 1, p. 149-174, nov. 2014. Disponível em: http://seer.pucgoias.edu.br/index.php/educativa/article/view/3598. Acesso em: 15 dez. 2020.

TANURI, Leonor Maria. História da formação de professores. Rev. Bras. Educ., Rio de Janeiro, n. 14, pág. 61-88, ago. 2000. Disponível em $<$ http://www.scielo.br/scielo.php?script=sci_arttext\&pid=S1413-

$24782000000200005 \& \operatorname{lng}=$ en\&nrm=iso $>$. Acesso em: 17 dez. 2021.

TARDIF, M.; RAYMOND, D. Saberes, tempo e aprendizagem do trabalho no magistério.

Educação \& Sociedade, Campinas, v. 21, n. 73, 2000. 
SOBRE OS AUTORES:

\section{Hortência Matias de Castro}

Mestranda no Programa de Pós-Graduação (PPGE/UEG). Efetiva na Rede Municipal de Educação da Prefeitura Municipal de Jaraguá/GO. Bolsista de Iniciação à Docência Interna (UEG). Correio eletrônico: hortenciacastro78@gmail.com

(iD https://orcid.org/0000-0003-3345-2946

\section{José Carlos Moreira de Souza}

Doutor em Educação (PPGE/FE - UFG). Docente do Ens. Básico Téc. e Tecnológico do Instituto Federal Goiano (IFGoiano, campus Ceres/GO) e Programa de Pós-Graduação em Educação Profissional e Tecnológica - ProfEPT. Membro de grupos de pesquisa no âmbito do ProfEPT/IFGoiano. Correio eletrônico: jose.moreira@ifgoiano.edu.br

iD https://orcid.org/0000-0002-1532-779X

Recebido em 12 de abril de 2021

Aprovado em 25 de agosto de 2021

Publicado em 03 de setembro de 2021 